\title{
In Vitro Study of Surface Condition of Orthodontic Wires after Immersion in Acid Media
}

\author{
Raoul Bationo $^{1 *}$, Claudia Quilodran-Naudon ${ }^{2}$, Fabienne Jordana ${ }^{3}$, Jacques Colat-Parros ${ }^{2}$ \\ ${ }^{I}$ CHU de Bogodogo, 14 BP 371 Ouagadougou 14, Burkina Faso \\ ${ }^{2}$ UFR des Sciences Odontologiques, 146 Rue Léo Saignat, 33076 Bordeaux, CHU Pellegrin, Bordeaux, France \\ ${ }^{3}$ UFR d'Odontologie de Nantes, 1 Place Alexis Ricordeau, BP 84215, 44042 Nantes cedex 1, France
}

Service d'Odontologie, CHU Nantes, 1 Place Alexis Ricordeau, 44093 Nantes cedex 1, France

*Corresponding Author: Raoul Bationo, CHU de Bogodogo, 14 BP 371 Ouagadougou 14, Burkina Faso. Email: raobat10@yahoo.fr

\begin{abstract}
The presence of orthodontic wires in oral environment as well as their proximity to other metal elements can lead to corrosion.

Wire segments from Nickel-Titanium and stainless steel of which some are submitted to a bending constraint are immersed in acid media and then observed under scanning electronic microscope.

The surface condition of the non-immersed segments is the result of manufacturing processes of the arcs. The wires immersed in Ringer + lactic acid have no signs of corrosion. However, distilled water + nitric acid has a corrosive action on the wires.

The corrosive behavior depends on the properties of the material, the manufacturing process, the environment, the $\mathrm{pH}$ values and the constraints.
\end{abstract}

Keywords: Nickel-Titanium alloy, Stainless Steel, Orthodontic wires, Corrosion

\section{INTRODUCTION}

In orthodontics, the wires placed in oral cavity are submitted to several constraints. An orthodontic arc like any other biomaterials will suffer a degradation caused by the oral environment.

The origin of degradation can be chemical, electrochemical or biological (microbial attack); corrosion is visible on the external surfaces of the biomaterial.

The superficial atomic layers are the first to act with the surrounding environment because they remain reactive from an electronic point of view. Then, corrosion can lead gradually to deep alterations in biomaterials.

The corrosion level of any metal depends on the chemical composition of the solvent in which it is immersed [1].

The corrosion of a material can be defined by progressive destruction, a slow disintegration, a crumbling of a substance or a surface by chemical effect. Corrosion can also be defined as a process of interaction between a solid material and its chemical environment, which causes a substance loss of material, a change in its structural characteristics or a loss of its structural integrity [2].

The corrosion of orthodontic devices in oral environment should be concern to practitioners as the absorption of corrosion products by the body could cause localized or systemic effects and physical properties as well as the clinical performance of the devices may be decreased [1].

The purpose of this study is to observe and compare the surface condition of orthodontic stainless steel and Nickel-Titanium wires before and after static immersion in acid environment.

\section{Materials and Methods}

Three maxillary arc wires with $0.016 "$ diameter are used.

- $\quad$ Speed Supercable (Speed System): Coaxial 6 strands, twisted

- Co-Ax Steel (American Orthodontics): Twisted, 6 strands

- Stainless Steel (American orthodontics): Monostrand 
The ends of the arcs are sectioned in order to obtain wire segments with a length of $50 \mathrm{~mm}$. A bending constraint is applied to a segment of each wire using an elastic.

Two segments of each wire with and without constraint are immersed in $2 \mathrm{ml}$ of each of the solutions ( $\mathrm{pH}$ 2) of Ringer + lactic acid (31 drops for $30 \mathrm{ml}$ ) and distilled water + nitric acid
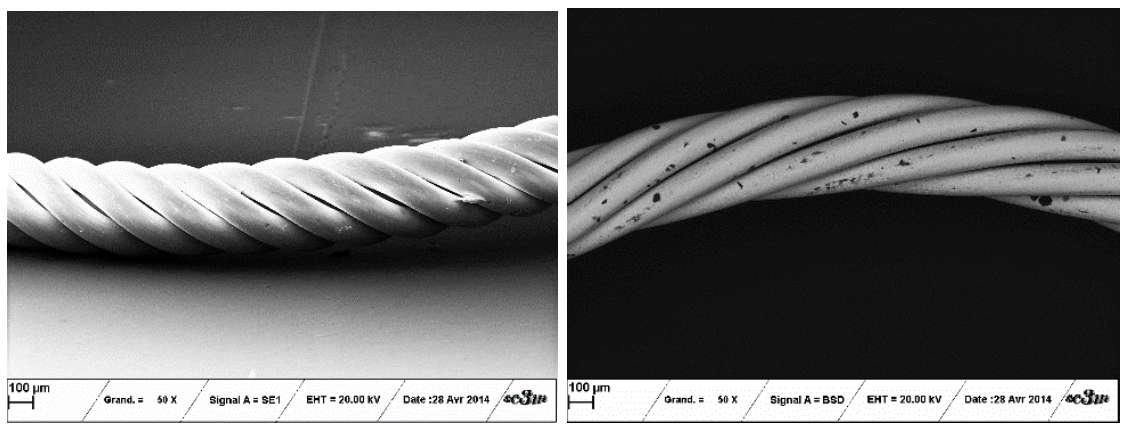

Figure1. Stress area of multistrand wires. Light distance of Co-Ax steel and Speed Supercable strands

The non-immersed segments have an inhomogenous not smooth surface. Some have longitudinal stripes and defects; others have a rough structure. The surfaces are the result of

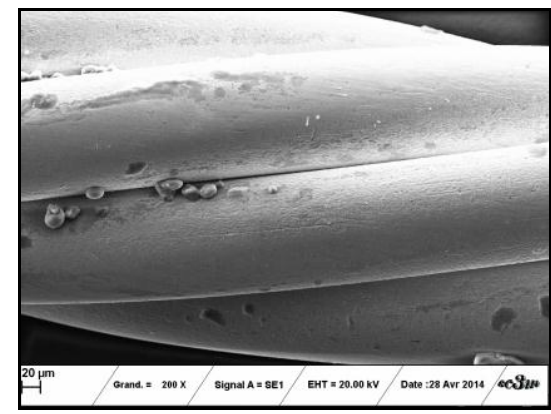
manufacturing process of the arcs. The Speed Supercable has the roughest surface. (Figures 2,3 and 4).

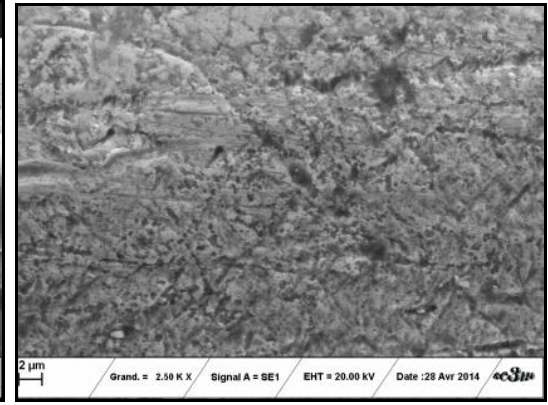

Figure2. Speed Supercable non-immersed. Rough and irregular surface with some impurities
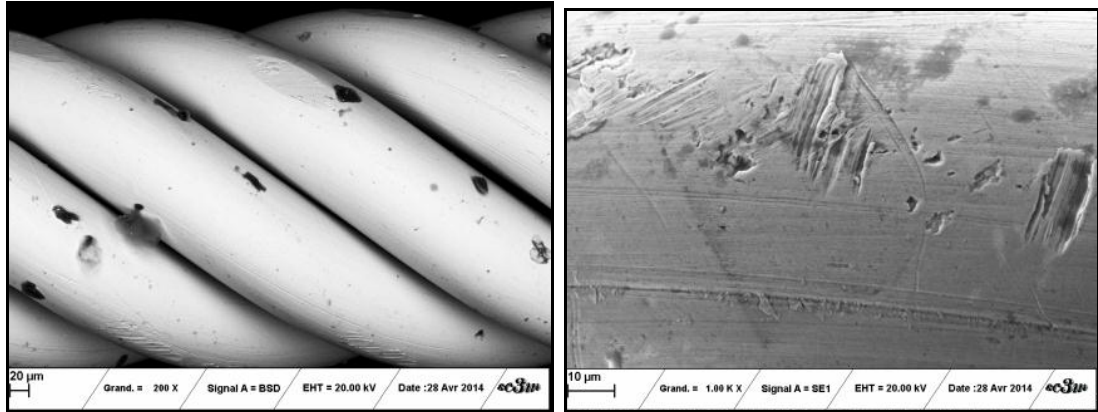

Figure3. Co-Ax steel non-immersed. Irregular surface with longitudinal marks and localized flaws
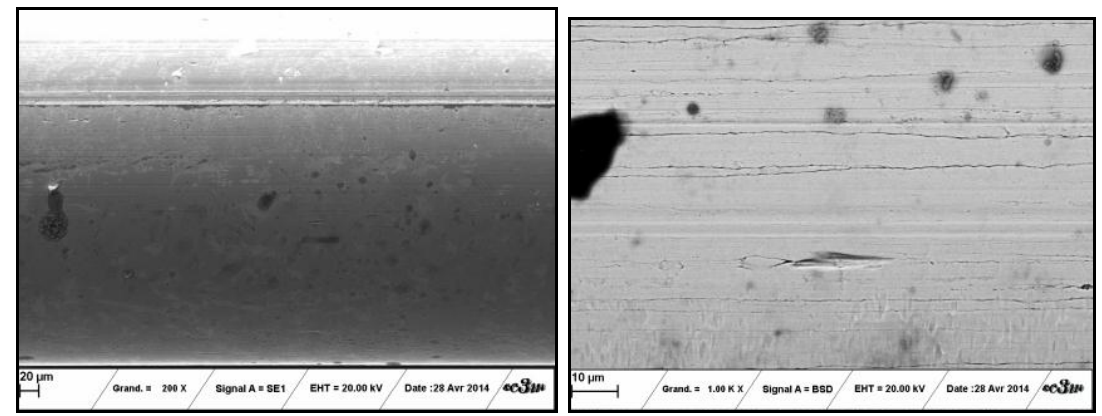

Figure4. Stainless Steel non-immersed. Longitudinal structure quite regular 
The immersed segments in Ringer + lactic acid present debris of the medium. The Speed Supercable, Co-Ax steel and Stainless Steel show no visible signs of corrosion.
In distilled water + nitric acid, the segments of Speed Supercable and Stainless Steel show signs of corrosion. The presence of impurities is noted with Co-Ax steel. (Figures 5 and 6).
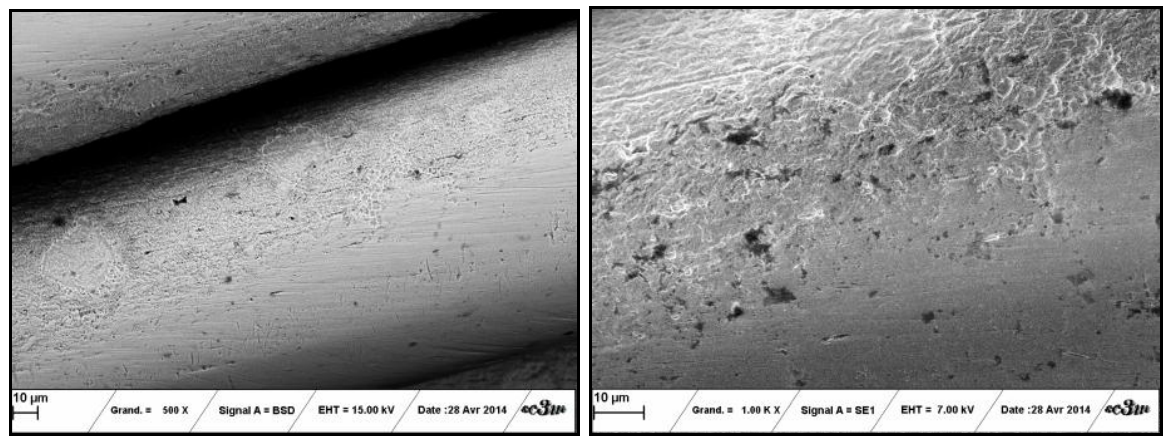

Figure5. Speed Supercable immersed in distilled water + nitric acid. Pickled structure, affected by injection corrosion
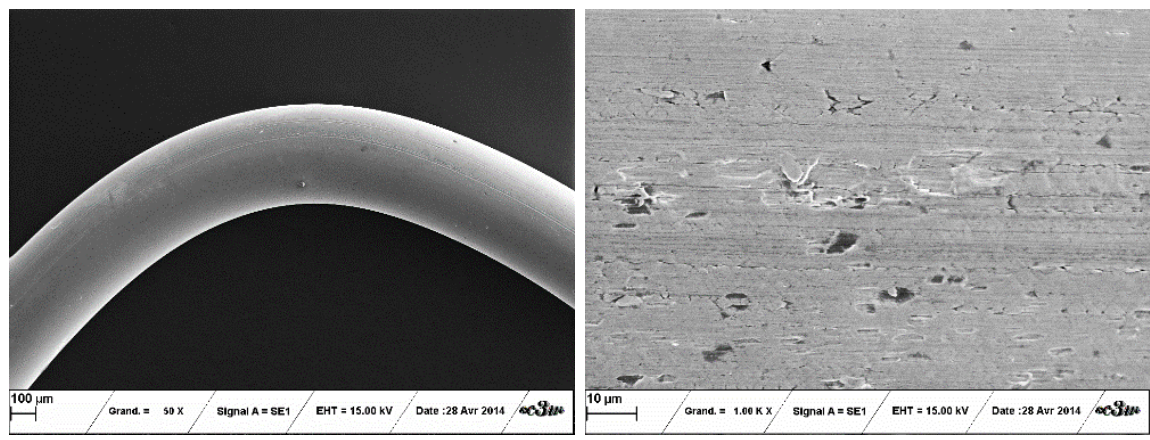

Figure6. Stainless Steel immersed in distilled water + nitric acid. Light corrosion signs

\section{DisCuSSION}

Variations in manufacturing techniques and finishing-polishing operations can affect the corrosion behavior of alloys.

The surface properties of the Nickel-Titanium are critically dependent on the used procedure [1]. It has been shown that resistance to localized corrosion of the Nitinol can vary considerably according to its surface condition [3].

Factors such as the chemical environment, the $\mathrm{pH}$, the temperature, the design of the equipment, the manufacturing process, the finishing of the surfaces, contamination and maintenance procedures can influence the corrosion of stainless steel; there are usually the types of localized corrosion [4].

According to Rondelli and Vicentini [5], the Nickel-Titanium alloy has a corrosive behavior generally comparable to that of stainless steel $18 \mathrm{Cr}-8 \mathrm{Ni}$, but as soon as the Nickel-Titanium passive layer is broken, the corrosion phenomenon accelerates in a greater proportion than steel. In the present study, the corrosive behavior of steel and Nickel-Titanium is similar, except for the Nickel-Titanium multistrand wire, which has a major susceptibility to corrosion. In the event that a breach of the passive layer occurs, the re-passivation would be slower for the Nickel-Titanium than for the steel.

Shabalovskaya et al. [6] said that inconsistent resistance to corrosion of the Nickel-Titanium could be attributed to the lack of chemistry understanding of its original surface and the lack of a standard surface treatment.

Nickel-Titanium wires would not have the same resistance to corrosion according to the different manufacturers. For Huang et al. [7], surface morphology and wire roughness are related to corrosion resistance.

The diffusion of metallic nickel may occur through defective layers of $\mathrm{TiO}_{2}$, which could be the case of layers affected by the constraint. The tension area of the constraint could be victim of micro tear at the surface of the wire, which would favor the release of nickel ions. These areas, with a defective layer of passivation, would be more corrosive. [8]

In this study, there were no visible differences between the areas submitted to constraint and the others.

On average, an orthodontic wire remains one to two months in the mouth; the effects of 
corrosion, that is to say the degradation of its structure and its surface are cumulative.

This in vitro study was done in static conditions. In clinical conditions, the wear and dislamination between wire and bracket could induce the corrosion phenomenon and thus increase the release of nickel ions. The corrosive behavior was very much dependent on the environment; in vivo tests would allow to have more reliable results. The use of artificial saliva was not possible due to the difficulty of getting a constant acid $\mathrm{pH}$ throughout the study.

The average $\mathrm{pH}$ of non-stimulated saliva in healthy patient is 6.8 , with variations between 5.9 and 7.5 [9] The saliva has the ability to neutralize the declines of $\mathrm{pH}$ (food intake, micro-organisms) by its buffer power and renewal within about 20 minutes [10]. The $\mathrm{pH} 2$ represents in this study an extreme situation that could not be clinically encountered. Other factors of environment that promote corrosive behavior, such as fluorine are not part of this study.

Despite the good corrosion resistance of NickelTitanium wires submitted to the constraints, there are fractures due to the degradation caused by corrosion in the oral environment [11].

The Nickel-Titanium fracture could be attributed to the degradation of mechanical properties due to the hydrogen absorption [12].

The corrosion increases friction force between the arc/bracket interfaces by the increase of the surface roughness. The result is an inappropriate distribution of forces on orthodontic devices and as a result, the efficacy of the dental movement decreases [13].

Nickel-Titanium wires degrade by adhesive wear while steel wires degrade by abrasive wear. The Nickel-Titanium wires would be more resistant to wear than steel wires [14].

Adding some metals to an alloy can reduce its predisposition to corrosion. This notion has been used in the production of Nickel-Titanium and orthodontic stainless steel. The corrosion resistance of Nickel-Titanium is due to the large proportion of titanium. In the case of Stainless Steel alloys, the addition of chrome and nickel gives resistance to corrosion. The addition of molybdenum can reduce the injection corrosion and the cavernous corrosion [1].

Several authors have tested the corrosion resistance of Nickel-Titanium alloys in different conditions. Lijima et al. [15] found this resistance in a saline physiological solution more important than that of steels or CobaltChrome alloys. Grosgogeat et al. [10] found the potential and the corrosion current of a NickelTitanium-Copper alloy very close to those of a classic Nickel-Titanium alloy. The corrosion resistance of Nickel-Titanium alloys is lower than that of the pure titanium.

The application of a constraint on an orthodontic wire does not seem to have any influence on localized corrosion phenomenon [16].

According to Huang [17,18], the composition and manufacturing of Nickel-Titanium wire, the $\mathrm{pH}$ and immersion time have an influence on corrosion rate but not on surface condition. The lower the $\mathrm{pH}$ is, the greater the corrosion rate.

In 2000, Eliades et al. [19] show that there is no difference in corrosion between anterior and posterior areas of an arc, between different manufacturers and between round, square or rectangular different sections.

Rondelli and Vicentini [20] confirm the noninfluence of the geometry of wire.

However, Wide et al. [21] report in their study significant differences in corrosion between Nickel-Titanium wires from different suppliers.

Eliades et al. [22] quantified the concentrations of metals into the saliva of orthodontic patients. They do not show any significant differences between a patient with steel arc and the one with Nickel-Titanium arc.

Toms [23] describes losses of size, change of forces applied on the teeth, risks of increased fracture and release of metal ions as consequences of the corrosion.

A study of Lijima et al. [15] shows that polishing a wire out of his commercial bag does not improve its resistance to corrosion. The layer of $\mathrm{TiO}_{2}$ improving corrosion resistance is influenced by the manufacturing process. However, in acid medium (lactic acid) this layer is put down and no longer plays its protective role.

The origin of alloys, the $\mathrm{pH}$ value and the immersion duration had a significant influence on the ions quantity of nickel and titanium released by the wires into artificial saliva [7].

Huang [18] shows that surface condition of a Nickel-Titanium wire is rougher than a conventional steel wire.

However, a rougher surface does not correspond to a greater loss of ions even if surface defects will be preferred sites for initiation of corrosion. 
Nickel-Titanium wires behave well in relation to corrosion phenomenon but that as soon as their protection layer is broken the phenomenon will be accelerated [24].

Nickel-Titanium alloys with a layer of aesthetic epoxy resin have better corrosion resistance and would be a good alternative for allergic patients [25].

\section{CONCLuSion}

Corrosive behavior depends on the properties of the material (chemical composition, microstructure), the manufacturing process, the environment, the $\mathrm{pH}$ values and the constraints.

It was not possible with the Scanning Electronic Microscope to see differences between surface condition of the areas submitted to a constraint and the others.

The corrosion effects, the degradation of the structure and the surface are cumulative.

There is a need to conduct clinical studies with more samples in order to achieve more appropriate and statistically significant results.

There is not yet a complete knowledge of corrosive behavior of alloys used in medical field; further studies would improve their applications (prostheses, implants...).

The surface condition is an important factor for corrosion. The rougher the surface is, the more likely it is to be attacked by corrosion especially the injection corrosion. The manufacturers must take this issue into account.

\section{ACKNOWLEDGEMENTS}

We thank team of INSERM, LIOAD, UMR 791 and that of the SC3M Platform of Nantes University.

\section{REFERENCES}

[1] House K, Sernetz F, Dymock D, Sandy JR, Ireland AJ. Corrosion of orthodontic appliances-should we care? Am J Orthod Dentofacial Orthop. 2008;133(4): 584-592.

[2] Jacobs JJ, Gilbert JL, Urban RM. Corrosion of metal orthopaedic implants. J Bone Joint Surg Am. 1998;80: 268-282.

[3] Clarke B, Carroll W, Rochev Y, Hynes M, Bradley D, Plumley D. Influence of Nitinol wire surface treatment on oxide thickness and composition and its subsequent effect on corrosion resistance and nickel ion release. $\mathrm{J}$ Biomed Mater Res A. 2006;79(1): 61-70.

[4] Tuthill AH, Roger A. Stainless Steels: An introduction to their metallurgy and corrosion resistance. Food and Environmental Sanitation. 2000;20(7): 506-517.

[5] Rondelli G, Vicentini B. Evaluation by electrochemical tests of the passive film stability of equiatomic $\mathrm{Ni}-\mathrm{Ti}$ alloy also in presence of stress-induced martensite. J Biomed Mater Res. 2000;51(1): 47-54.

[6] Shabalovskaya S, Anderegg JW, Undisz A, Rettenmayr M, Rondelli GC. Corrosion resistance, chemistry, and mechanical aspects of Nitinol surfaces formed in hydrogen peroxide solutions. J Biomed Mater Res B Appl Biomater. 2012;100(6): 1490-1499.

[7] Huang HH, Chiu YH, Lee TH, Wu SC, Yang $\mathrm{HW}$, Su KH, Hsu CC. Ion release from NiTi orthodontic wires in artificial saliva with various acidities. Biomaterials. 2003;24(20): 3585-3592.

[8] Espinos JP, Fernandez A, Gonzalez-Elipe AR. Oxidation and diffusion processes in nickeltitanium oxide systems. Surface science. 1993;295: 402-410.

[9] Fenoll-Palomares C, Munoz Montagud JV, Sanchiz V, Herreros B, Hernandez V, Minguez $\mathrm{M}$, Benages A. Unstimulated salivary flow rate, $\mathrm{pH}$ and buffer capacity of saliva in healthy volunteers. Rev Esp Enferm Dig. 2004;96(11): 773-783.

[10] Grosgogeat B, Pernier C, Schiff N, Comte V, Huet A. Resistance à la corrosion et biocompatibilité des fils orthodontiques. Orthod Fr. 2003;74(1): 115-121.

[11] Hunt NP, Cunningham SJ, Golden CG, Sheriff M. An investigation into the effects of polishing on surface hardness and corrosion of orthodontic archwires. Angle Orthod. 1999;69(5): 433-440.

[12] Szustakiewicz B, Djerbi N, Gondy A, Derki M, Devulder-Salana A, Pindi G, et al. Behavior of materials in the oral environment. Orthod Fr. 2009;80(1): 99-135.

[13] Schwaninger B, Sarkar NK, Foster BE. Effect of long-term immersion corrosion on the flexural properties of nitinol. Am J Orthod. 1982;82(1): 45-49.

[14] Berradja A, Willems G, Celis J-P. Tribological behaviour of orthodontic archwires under dry and wet sliding conditions in-vitro. II - Wear patterns. Aust Orthod J. 2006;22(1): 21-29.

[15] Lijima M, Endo K, Ohno H, Yonekura Y, Mizoguchi I. Corrosion behaviour and surface structure of orthodontic Ni-Ti alloy wires. Dent Mat Res. 2001;20(1): 103-113.

[16] Segal N, Hell J, Berzins DW. Influence of stress and phase on corrosion of a superelastic nickel-titanium orthodontic wire. Am J Orthod Dentofacial Orthop. 2009;135: 764-770.

[17] Huang HH. Corrosion resistance of stressed NiTi and stainless steel orthodontic wires in acid artificial saliva. J Biomed Mater Res. 2003;66: 829-839.

[18] Huang HH. Surface characterizations and corrosion resistance of nickel-titanium 
orthodontic archwires in artificial saliva of various degrees of acidity. J Biomed Mater Res A. $2005 ; 74(4)$ : 629-639.

[19] Eliades T, Eliades G, Athanasiou AE, Bradley TG. Surface characterization of retrieved NiTi orthodontic archwires. Eur J Orthod. 2000;22: 317-326.

[20] Rondelli G, Vicentini B. Localized corrosion behaviour in simulated human body fluids of commercial NiTi orthodontic wires. Biomaterials. 1999;20: 785-792.

[21] Widu F, Drescher D, Junker R, Bourauel C. Corrosion and biocompatibility of orthodontic wires. J Mater Res Mat Med. 1999;10: 275281.
[22] Eliades T, Trapali S, Eliades G, Katsavrias E. Salivary metal levels of orthodontic patients: a novel methodological and analytical approach. Eur J Orthod. 2003;25: 103-106.

[23] Toms AP. The corrosion of orthodontic wire. Eur J Orthod. 1988;10(2): 87-97.

[24] Rondelli G. Corrosion resistance tests on NiTi shape memory alloy. Biomaterials. 1996; 17 (20): 2003-2008.

[25] Kim H, Johnson W. Corrosion of stainless steel, nickel-titanium, coated nickel-titanium, and titanium orthodontic wires. Angle Orthod. 1999;69(1): 39-44.

Citation: Raoul Bationo et al. In Vitro Study of Surface Condition of Orthodontic Wires after Immersion in Acid Media. ARC Journal of Dental science. 2019; 4(4):8-13. doi:dx.doi.org/10.20431/2456-0030.0404003.

Copyright: (C) 2019 Authors. This is an open-access article distributed under the terms of the Creative Commons Attribution License, which permits unrestricted use, distribution, and reproduction in any medium, provided the original author and source are credited. 